\title{
Socioeconomic potential for introducing large- scale heat pumps in district heating in Denmark
}

\author{
Rasmus Lund, Danica Djuric Ilic and Louise Trygg \\ Journal Article
}

Tweet

N.B.: When citing this work, cite the original article.

Original Publication:

Rasmus Lund, Danica Djuric Ilic and Louise Trygg, Socioeconomic potential for introducing large-scale heat pumps in district heating in Denmark, Journal of Cleaner Production, 2016. 139(), pp.219-229.

http://dx.doi.org/10.1016/j.jclepro.2016.07.135

Copyright: Elsevier

http://www.elsevier.com/

Postprint available at: Linköping University Electronic Press

http://urn.kb.se/resolve?urn=urn:nbn:se:liu:diva-132978

(c)

1.UU UNWENGRS 


\section{Title information}

\section{Title}

Socioeconomic Potential for Introducing Large-Scale Heat Pumps in District Heating in Denmark

Authors

Rasmus Lund ${ }^{a}$ (Corresponding author: rlund@plan.aau.dk, +45 9940 2421),

Danica Djuric llic ${ }^{b}$ (danica.djuric.ilic@liu.se),

Louise Trygg (louise.trygg@liu.se)

\section{Affiliation}

${ }^{a}$ Department of Development and Planning, Aalborg University, A. C. Meyers Vænge 15, 2450 Copenhagen, Denmark

${ }^{b}$ Department of Management and Engineering, Linköping University, 58183 Linköping, Sweden

Keywords

Heat pump

District heating

Energy system analysis

Combined heat and power (CHP)

Renewable energy

Energy sector integration

\section{Word count}

In total 6,708 words in the document. 


\section{Socioeconomic Potential for Introducing Large-Scale Heat Pumps in District Heating in Denmark}

\section{Abstract}

Denmark has a national political goal of a $100 \%$ renewable energy supply in 2050 . This requires a comprehensive transition of the energy system. For some decades, district heating in Denmark has been contributing to high fuel efficiency as well as to the integration of the electricity and heating sectors. Largescale compression heat pumps would improve the integration between the district heating and power sectors by utilising the fluctuations in the supply from wind power, solar photo voltaic and other sources. Previous studies indicate that the introduction of heat pumps in Denmark will have a positive impact on the total costs for energy supply in the transition towards $100 \%$ renewable energy. In this paper, this is further investigated to assess the feasibility of heat pumps in the Danish energy system. The assessment is made by applying two different energy system analysis tools, named EnergyPLAN and MODEST. The comparison and discussion of these tools is a secondary purpose of the study. In general, the results show a potential for introducing heat pumps in Denmark between 2 and $4 \mathrm{GW}$-thermal power and a total potential benefit around $100 \mathrm{M} € /$ year in 2025.

\section{List of Abbreviations}

CHP Combined Heat and Power

COP Coefficient of performance

$\mathrm{DH} \quad$ District Heating

HP(s) Heat Pump(s)

RE Renewable Energy 


\section{Introduction}

The national political goal for the Danish energy system is to have a $100 \%$ renewable energy (RE) supply in 2050 (The Danish Government, 2012). This involves a transformation of the existing energy system, which is at present supplied with approximately 73\% fossil based energy (Danish Energy Agency, 2015a). Currently, the transition is challenged by extraordinary low electricity prices, which reduce the short-term feasibility of wind turbines and the incentive to invest in new turbines. The low electricity prices also limit the operation of combined heat and power (CHP) plants in district heating (DH) systems. Hence, CHP is replaced with heat production in biomass based heat-only boilers and the incentive to reinvest in CHP capacity is small. This is reflected in the Danish transmission system operator's projection of the CHP capacity in Denmark, which is expected to decrease significantly during the coming decades. See Figure 1.

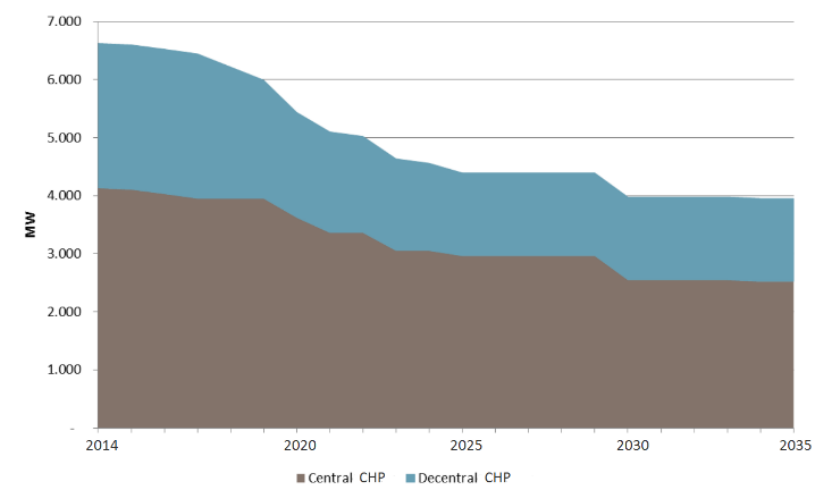

Figure 1 Projected development in CHP capacity in Denmark for central and decentralised CHP plants (Energinet.dk, 2015).

This development will reduce the general fuel efficiency of the energy supply in Denmark and heat pumps (HPs) are often suggested as a solution to this. HPs can increase demand for electricity and produce heating at a high efficiency replacing production in heat-only boilers. HPs are generally not a feasible technology for the $\mathrm{DH}$ plants to invest in because of the current tax structure. It will require a revision of the regulatory framework for HPs in DH to become feasible. In the neighbour countries Sweden, Norway and Finland, which have similar conditions as Denmark, there are already large HPs operating in DH. In (Clausen et al., 2014) a number of examples are given from these countries above $10 \mathrm{MW}$-scale per plant, and using different heat sources.

\subsection{Related Studies}

In the transition towards $100 \% \mathrm{RE}$, the biomass used for energy supply is an increasingly critical resource, as it is the only naturally available fuel that can directly substitute fossil fuels. Hence, the biomass resources used in energy systems should be prioritised for purposes where fuel is needed or for process energy where other options are not viable. This is discussed further in (Mathiesen et al., 2012). Andersen and Lund (2007) present one solution to strengthen the position of CHP plants by establishing new partnerships between decentralised CHP plants. Thereby, the plants become able to deliver new electricity system services by cooperating on bidding in the electricity markets. Karschin and Geldermann (2015) also focus on the fuel efficiency of using CHP for heat production recognising the availability of biomass resources as a parameter in planning for systems based on RE. 
According to Connolly and Mathiesen (2014), the development towards a $100 \%$ RE system requires a combination of $\mathrm{DH}$ and flexible HPs to integrate the fluctuating energy sources in the most feasible way. Thermal storage in the DH system is needed to allow HPs and CHP to operate more independent of heat demand and electricity prices. As larger capacities of fluctuating power supply is introduced, other storage technologies may be needed as well. Even the island of Sams $\varnothing$, which is known for innovative solutions; is a net-exporter of RE and can be seen as a front runner on RE in Denmark, has no HPs in its DH supply, but a large share of biomass boiler production (Nielsen and Jørgensen, 2015). For the context of Greater Copenhagen, Bach et al.(2016) have analysed the potential for using large HPs in the DH supply, considering different heat sources and COP's. The results indicate that there is a potential for HPs in the region but do not conclude on overall feasibility.

A number of studies have shown that HPs have a potential for integrating fluctuating renewable heat and electricity production. Pensini et al. (2014) show how fuels for heating can be replaced with electricity from renewable sources by using HPs. Ommen et al. (2014) suggest and assess a number of specific ways of integrating HPs in DH. Blarke and Dotzaur (2011) suggest a new concept of integrating CHP and HP units creating a more intermittency-friendly system. This indicates that a higher capacity of HPs will increase the ability of the system to integrate fluctuating renewable electricity sources. In Blarke (2012), HPs are compared with electric boilers in terms of cost effectiveness for that same purpose.

\subsection{Contribution of the Present Study}

The purpose of this study is two-fold. The primary purpose is to assess the economic potential for introducing HPs in DH in Denmark. The secondary purpose is to compare and assess the differences of two types of tools for performing the analysis. This is done by developing energy system models for the Danish energy system in 2013 and 2025, respectively, and identifying the economically optimal capacities of HPs in these models. This analysis is done in two different energy systems analysis tools, EnergyPLAN and MODEST, and the results and differences are compared and discussed. The knowledge produced can support political decisions on the energy system development in Denmark.

Chapter 2 presents central theoretical considerations and methods regarding the energy systems modelling followed by Chapter 3, which presents the concrete applied analysis assumptions. In Chapter 4 the results of the analysis is discussed and in Chapter 5, conclusions are given.

\section{Theory and Methods}

In this chapter, the main theoretical concepts and background for the choice of the modelling tools are elaborated.

\subsection{A System Approach}

To apply a system approach is a way of thinking (Churchman, 1968) about the total studied system and its components. According to Wallén (1996), a wide definition describes a system as a group of objects that interact. As a totality, the system has qualities which are more diverse than what can be expected in the single objects. Also Ingelstam (2002) claims that a system entails two types of parameters: the components of the system and the connection between them. In system analyses, it is vital to identify the connections between the different components of the system and the interaction between them as well as to interpret the system itself. 
When conducting a system analysis, the first assignment is to find an appropriate delimitation: what is inside and what is outside the system. In addition to system delimitation, some of the main points in theoretical system analyses are the creation of a system and studies of, for example, energy flows inside the system and flows between the system and the surroundings; connections between the different parts of the system, and how the system alters over time (Wallén, 1996).

\subsection{Theory of Energy System Analysis}

Energy systems can be seen as networks connecting sources of energy with end-use demands through various conversion and storage technologies and energy grids transporting the different types of energy.

Energy system analysis tools are computation tools to structure and simplify the complexity of the real energy systems in models describing the energy sources, conversion technologies, energy flows, etc., in a systematic way. The model forms the basis for making analyses of issues related to the modelled system.

The modelling is the process of establishing the framework and a starting point for the analysis. This can include the definition of available energy sources, capacities of conversion and storage technologies and energy demands. The analysis is the way in which the computation tool handles the data in the model together with possible analysis parameters. The combination of these two and the possible analysis outputs makes the tool fit a specific type of application. See Figure 2.

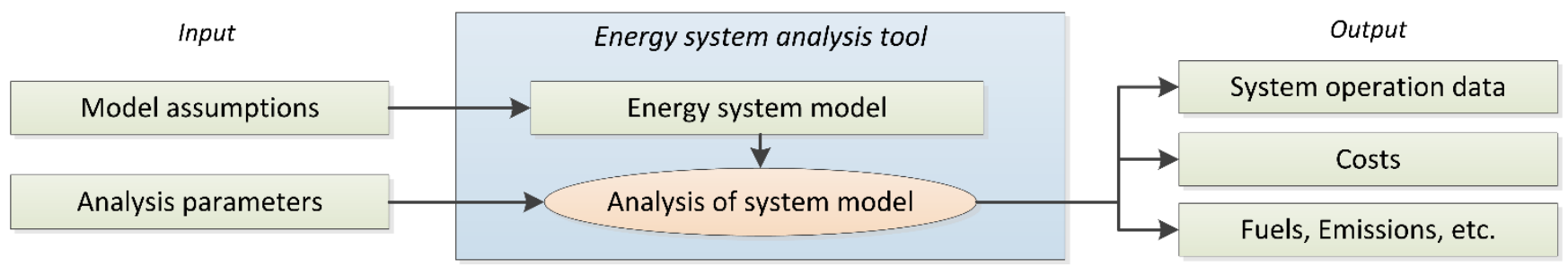

Figure 2 Conceptual diagram of energy system analysis tool with inputs and possible outputs.

Lund points out in (Lund, 2014) that all energy system analysis tools are developed with a specific purpose and with the ability to handle a specific type of energy systems and analysis questions. It is important to be aware of this when choosing a tool for analysis. Hence, some tools might be used for an analysis that answers a question outside the scope and purpose of the tool, which might generate misleading results.

\subsection{Choice of Energy System Analysis Tools}

Since the purpose of this study is to investigate the potential for introducing large-scale HPs in DH in Denmark, where the electricity production from wind and solar is expected soon to reach $50 \%$ of the demand, the analysis tools should be suited for this application.

Lund discusses in (Lund, 2014) two main challenges of modelling and analysing energy systems with large shares of fluctuating and intermittent energy sources. The first challenge is handling the fluctuations in a way that reflects the dynamic behaviour of the energy system and the interaction between the components of the system. The other challenge is limiting the biomass consumption to a sustainable level in the development towards an energy system based on $100 \%$ RE.

Segurado et al. (2009) compare a number of energy systems analysis tools in terms of a series of chosen parameters. This includes types of database availability and abilities to perform cost and environmental 
analyses. A similar approach is applied by Connolly et al., who review 37 different energy system analysis tools and divide the tools according to a number of parameters relevant to the analysis of integration of RE (Connolly et al., 2010). Following Connolly's arguments, a number of requirements to the tool can be extracted for this study:

1) Handling of a national energy system

2) Analyse large-scale integration of fluctuating RE sources

3) Model the integration of $\mathrm{DH}$ and electricity sectors

4) Calculate system costs

5) Presenting detailed computational data of the model analyses

Lund argues in (Lund, 2014) that 100\% RE systems should be modelled taking into account the variation from hour to hour in the energy system to capture the dynamics in the system properly. In a system with only a small share of fluctuating RE, it may be sufficient to make a calculation without account for hourly variations. However, with $50 \%$ electricity supplied from wind and solar power, this case can be regarded as large-scale integration, which according to Lund requires an hourly calculation.

Following the discussion of the requirements to tools for the stated purpose in this chapter, the two tools EnergyPLAN and MODEST have been chosen. These tools can be seen as complementary as EnergyPLAN has a high temporal resolution, whereas MODEST performs a numerical optimisation. Individually, both tools are suitable for the given purpose, but at the same time the tools perform differently in the analysis. This gives an opportunity for the comparison of results and an assessment of the sensitivity of the results to the choice of tool type.

\subsection{The EnergyPLAN Tool}

EnergyPLAN is designed to model and analyse the large-scale integration of RE and $100 \%$ RE systems. EnergyPLAN has an inbuilt model of an energy system, defining the possible energy source, conversion units, demands, etc., and the flows between them. This is a very thorough model enabling analyses of many different types of technologies and energy sources, but the user cannot define new types of conversion units that do not already exist in the model. The user has to provide inputs in the form of installed output capacities, efficiencies, fuel mix, costs and demands.

It can be defined in the model how the system should optimise and which solutions should be given priority. The optimisation is based on analytical programming, which means that the optimisation strategies are based on a predefined merit order of the technologies based on the resource efficiency of the technologies and the lowest marginal operation costs, among others. This means that the system does not seek to find an optimal solution as such, but rather simulates how the system operates under given priorities.

The tool works on an aggregated level in the sense that not every plant is modelled, but all plants of the same type are modelled as one. This enables the tool to model and analyse national energy systems in a way that is not too time consuming, as in Connolly and Mathiesen (2014) where the energy system of Ireland is analysed. The tool is able to model the large-scale integration of RE by the use of a variety of technologies for conversion between different forms of energy (electricity, heat, gas, hydrogen, etc.). This enables the tool to integrate the energy sectors, for example CHP plants, HPs, electric boilers, electrolysis plants and electric vehicles. These are modelled on an hourly basis to take into account the fluctuations in the production and demands and to enable 
the storage between energy sectors. This is described under the "Smart Energy Systems" concept in the review article in Mathiesen et al. (2015a).

In EnergyPLAN, the annual system costs can be calculated, which include annuity of investments, fixed and variable costs and fuel costs. The tool does not include a dedicated investment optimisation function, but the optimal capacity of, e.g., HPs can be found in an iterative process manually changing the capacity, thus reaching a minimum of total system costs. Furthermore, the tool provides very detailed results of the calculations, at hourly resolution if needed and for all system flows. This makes the results transparent and it makes the review of the details of a certain simulation very easy.

\subsection{The MODEST Tool}

MODEST is a tool for the optimisation of dynamic energy systems with time-dependent components and boundary conditions. General input data that need to be defined when building a model in MODEST are studied period, time division, discount rate and the energy demands that must be fulfilled (e.g. heat, biofuel, electricity, cooling). Besides the demand nodes, the other elements in the model are networks, plants, start nodes (such as fuels), and so-called "waste nodes". These "waste nodes" open up possibilities for producing more electricity for purposes of export, producing excess heat in order to increase the electricity production, or even producing other by-products (e.g. biofuels or pellets). The plants in the model are described in terms of their efficiencies, maximum capacity, power-to-heat ratio (if it is a CHP plant), maintenance periods and costs, technical and economic lifespans, and possible investment cost (Gebremedhin, 2003; Henning, 1999).

The aim of the optimisation is to minimise the system cost of supplying the defined energy demands during the analysed period. The system cost includes: new investments, operation and maintenance costs, fuel costs including taxes and fees, as well as revenues from by-products, and lastly, the present value of all the capital costs. The optimisation is performed by choosing the best operation at each time period from existing and potential new plants in the system. Besides the system costs, other outputs from the tool are, e.g., detailed data about the fuel and electricity use, detailed data about productions from the plants and data related to delivering through the networks.

During the last 20 years, MODEST has been applied to different kinds of energy systems with different purposes. In most of these studies, a time division where each year is divided into 88 periods is used. This time division is developed in order to depict seasonal, weekly and diurnal variations in the heat demand and electricity prices. The time division is described in more detail in (Henning et al., 2006). However, a new distribution of hours has been made for this analysis to better reflect the fluctuations in the wind power production. This time division consists of 96 periods. Every month, hours are divided into the following eight "groups" of hours:

- Monday-Friday 8-13

- Monday-Friday 13-18

- Monday-Friday 18-22

- Monday-Friday 22-8

- Saturday, Sunday and Holidays 8-22

- Saturday, Sunday and Holidays 22-8

- High wind (72 highest hours) 
- Low wind (144 lowest hours)

Here, it is emphasised that the hours with extreme wind conditions, either high or low, will be handled individually. This improves the system sensitivity to fluctuations in the wind production.

\section{Modelling Assumptions and Input Data}

In this chapter, the structure of the research performed for this study is described and the applied assumptions and inputs data are presented.

\subsection{Model of the Energy System in Denmark}

The model of the Danish energy system used in this study is shown in Figure 2 . The nodes and flows defining the models are described using a number of parameters and characteristics, such as annual production, efficiencies, conversion capacities, costs, etc., which differ between the scenarios. These specific assumptions are presented in Section 3.3. However, the general system of nodes and flows, shown in Figure 2, is the same in all scenarios and analyses.

The model is structured according to three $\mathrm{DH}$ groups which represent different types of $\mathrm{DH}$ systems. The $\mathrm{DH}$ groups are defined as follows:

DH Group 1) Decentralised DH systems without CHP units

DH Group 2) Decentralised DH systems with back pressure CHP units

DH Group 3) Centralised DH systems with extraction CHP plants

The three groups are included to take into account the differences in heat sources and possibilities of interaction with the electricity system. These differences create different potentials for the integration of HPs and electric boilers. The results, presented in Section 4, are not divided into DH Groups, but the details can be found in Appendix. 


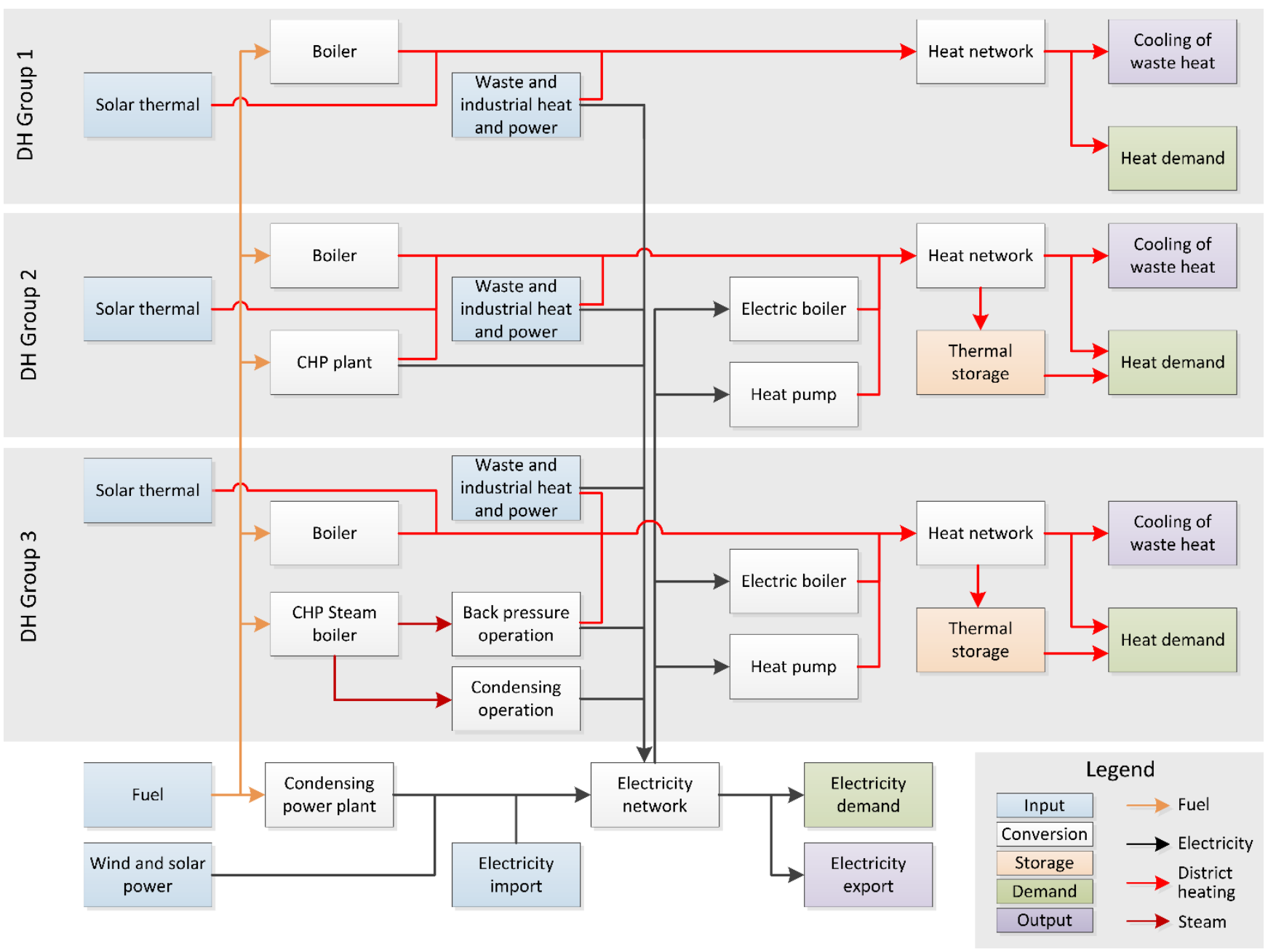

Figure 3 Schematic diagram showing the model of the energy system for Denmark implemented in the analysis tools. The DH (District heating) groups 1-3 refer to the interaction with the electricity grid. (1. DH without CHP, 2. DH with back pressure CHP and 3. DH with extraction $\mathrm{CHP}$ ).

\subsection{Scenarios}

The two scenario years for the study have been chosen, 2013 and 2025, to be able to conclude on the current and near future potential for introduction of heat pumps in $\mathrm{DH}$.

\subsubsection{Energy System Assumptions}

The parameters in the scenario related to the year 2013 are based on statistical data for the year 2013 (Danish Energy Agency, 2014a). The year 2013 has been chosen because this was the latest year where all needed data for the modelling were available. This scenario is documented further in connection to the project IDA Climate Vision in Mathiesen et al. (2015b) and is used as a point of reference when the 2025 scenario is discussed. The scenario for 2025 is based on the statistical data for 2013 combined with a projection of the DH and power sector development made by the Danish Energy Agency (2014b).

In Table 1, the main energy system parameters are presented. 
Table 1 Main energy system parameters for the two analysed scenarios; 2013 and 2025. The DH (District heating) groups 1-3 refer to the interaction with the electricity grid. (1. DH without CHP, 2. DH with back pressure CHP and 3. DH with extraction CHP). (Danish Energy Agency, 2014a, 2014b)

\begin{tabular}{|c|c|c|c|}
\hline Parameter & Unit & 2013 & 2025 \\
\hline \multicolumn{4}{|l|}{ Electricity } \\
\hline Electricity demand & TWh/year & 34.22 & 36.93 \\
\hline Wind power production & TWh/year & 11.12 & 19.91 \\
\hline Solar PV production & TWh/year & 0.52 & 3.06 \\
\hline Waste and industrial power production & TWh/year & 3.59 & 3.59 \\
\hline Condensing power capacity & MW & 6,244 & 4,890 \\
\hline Import/export capacity & MW & 5,450 & 8,765 \\
\hline \multicolumn{4}{|l|}{ DH group 1} \\
\hline Heat demand & TWh/year & 2.7 & 2.7 \\
\hline Heat loss & $\%$ & 0.2 & 0.2 \\
\hline Waste and industrial heat production & TWh/year & 0.91 & 0.91 \\
\hline \multicolumn{4}{|l|}{ DH group 2} \\
\hline Heat demand & TWh/year & 8.5 & 8.4 \\
\hline Heat loss & $\%$ & 0.2 & 0.2 \\
\hline Waste and industrial heat production & TWh/year & 1.95 & 1.95 \\
\hline Solar thermal production & TWh/year & 0.14 & 1.0 \\
\hline CHP capacity & MW-e & 1,889 & 1,541 \\
\hline CHP electric efficiency & $\%$ & 0.36 & 0.36 \\
\hline CHP thermal efficiency & $\%$ & 0.4 & 0.4 \\
\hline Thermal storage capacity & GWh & 33.2 & 33.2 \\
\hline \multicolumn{4}{|l|}{ DH group 3} \\
\hline Heat demand & TWh/year & 19.4 & 19.2 \\
\hline Heat loss & $\%$ & 0.15 & 0.15 \\
\hline Waste and industrial heat production & TWh/year & 3.82 & 3.82 \\
\hline Solar thermal production & TWh/year & 0 & 0.3 \\
\hline CHP capacity & MW-e & 4,852 & 3,800 \\
\hline CHP electric efficiency & $\%$ & 0.31 & 0.31 \\
\hline CHP thermal efficiency & $\%$ & 0.45 & 0.45 \\
\hline Thermal storage capacity & GWh & 15.7 & 15.7 \\
\hline
\end{tabular}

\subsubsection{Cost Assumptions}

The system costs are calculated as socioeconomic costs, which include investments, operation and maintenance, fuel, electricity import and export. System costs do not include taxes, subsidies or levies, because these represent a redistribution of costs rather than actual costs. The term feasible is used in this paper to say that something has a positive socioeconomic contribution. The main cost assumptions included in the study are presented in Table 2. The energy prices for the 2013 scenario are based on statistics from the Danish Energy Agency (Danish Energy Agency, 2013) and those for 2025 are from the fuel price prediction in Danish Energy Agency (2014b). Technology investment costs are from "Technology Data for Energy Plants" (Danish Energy 
Agency, 2015b). A socioeconomic discount rate of 3\% is applied for the investment costs (Dyrelund et al., 2010). Investment costs for included technologies not mentioned in Table 2, fixed and variable operation costs and technical investment lifetime are included in the calculations, but not presented here since these have a minor influence on the results. These can be found in the references as presented above.

Table 2 Main economic assumptions for the two analysed scenarios; 2013 and $2025 .{ }^{1}$ The hourly price distribution of 2013 is scaled to the given level for 2025.

\begin{tabular}{llrr}
\hline Parameter & Unit & $\mathbf{2 0 1 3}$ & $\mathbf{2 0 2 5}$ \\
\hline Energy prices & & & \\
\hline Coal & $€ / G J$ & 3.1 & 3.3 \\
Oil & $€ / G J$ & 15.0 & 18.7 \\
Natural gas & $€ / G J$ & 9.1 & 9.6 \\
Biomass & $€ / G J$ & 7.3 & 8.1 \\
Electricity price (year average) & $€ / M W h$ & 38.0 & $45.0^{1}$ \\
Investment costs & & & 1.8 \\
\hline Large-scale HPs & M€/MW-th & 2.5 & 0.1 \\
Electric boiler & M€/MW-e & 0.1 & \\
\hline
\end{tabular}

\subsection{Analysis Procedure and Sensitivity Analysis}

The analysis consists of a number of calculations using the two tools, where key parameters are altered to enable the assessment of the sensitivity of the results to these parameters. For every time a parameter is altered, the optimal capacity of HPs is found corresponding to the minimum total system costs - referred to as the potential. Electric boilers are included in the calculations as an option as well.

Baseline calculations. Initially the scenarios are calculated in both of the tools without any HP capacities as a point of reference.

Closed system calculations. The closed systems are without any electricity import/export capacity to neighbouring regions. The purpose of these calculations is to compare the operation of the model in the two different tools. This configuration is also used in the calibration of the model in the two tools.

Electricity and fuel prices. The electricity and fuel price levels can have a significant impact on the feasibility of HPs because of the markets in which the HPs compete, i.e. DH production and electricity consumption. In this analysis, the price levels are each increased and reduced by $33 \%$. See the assumed values in Table 3.

Table 3: Assumed data for electricity and fuel price levels in the baseline, high and low configurations.

\begin{tabular}{lrrrrr}
\hline (€/MWh) & $\begin{array}{r}\text { Electricity } \\
\text { (average) }\end{array}$ & Coal & Oil & Natural gas & Biomass \\
\hline Baseline assumption & 45.0 & 11.9 & 67.4 & 34.4 & 29.3 \\
High value & 60.0 & 15.8 & 89.6 & 45.8 & 39.0 \\
Low value & 30.0 & 7.9 & 44.9 & 22.9 & 19.5 \\
\hline
\end{tabular}


Investment costs and coefficient of performance (COP) of HPs. The investment costs and COP of the HPs are both related the technological development and the choice of heat source for the HPs. The COP of the HPs is related to the temperature level in both the heat source and the DH networks. No specific temperature levels are considered in this study, but the assumed COP is representing a mix of DH networks and heat sources with different temperature levels. In the future, if temperature levels in general are reduced, the COPs will increase. The investment cost is changed with $+/-33 \%$ in the analysis and the achievable average COP is changed with +/- 0.5. The applied values are shown in Table 4.

Table 4: Assumed values for the heat pump technology parameters; investment cost and COP for the baseline, high and low configurations.

\begin{tabular}{lrr}
\hline & $\begin{array}{r}\text { Investment cost } \\
(€ / \mathrm{MW} \text {-th) }\end{array}$ & COP \\
\hline Baseline assumption & 600,000 & 3.0 \\
High value & 800,000 & 3.5 \\
Low value & 400,000 & 2.5 \\
\hline
\end{tabular}

\section{Results and Discussion}

In the first part of this chapter the results of the analysis of the feasible HP capacities in Denmark applying the base line assumptions are presented. In the second section, the main uncertainties related to external conditions and modelling assumptions are presented and discussed. Detailed operational output data for the calculations from the two tools can be found in the Appendix.

\subsection{Feasibility and Potential of Heat Pumps}

In Figure 3, the main results are presented for the two scenarios. The Reference scenarios show the total system costs of the systems without any HP or electric boiler capacities. The Potential scenarios show the costs of operating a system with optimal capacities.

It can be seen that MODEST identifies higher HP capacities and slightly higher total system costs than EnergyPLAN, but in the same order of magnitude. It can also be seen that both tools find a socioeconomic potential for introducing HPs in both of the scenarios and that the potential in 2025 is significantly higher than in 2013. The socioeconomic benefit of investing in the optimal HP capacity is about $100 \mathrm{M} €$ /year in 2025, considering the reduced costs in the system. See Table 5 in the Appendix for more details. 


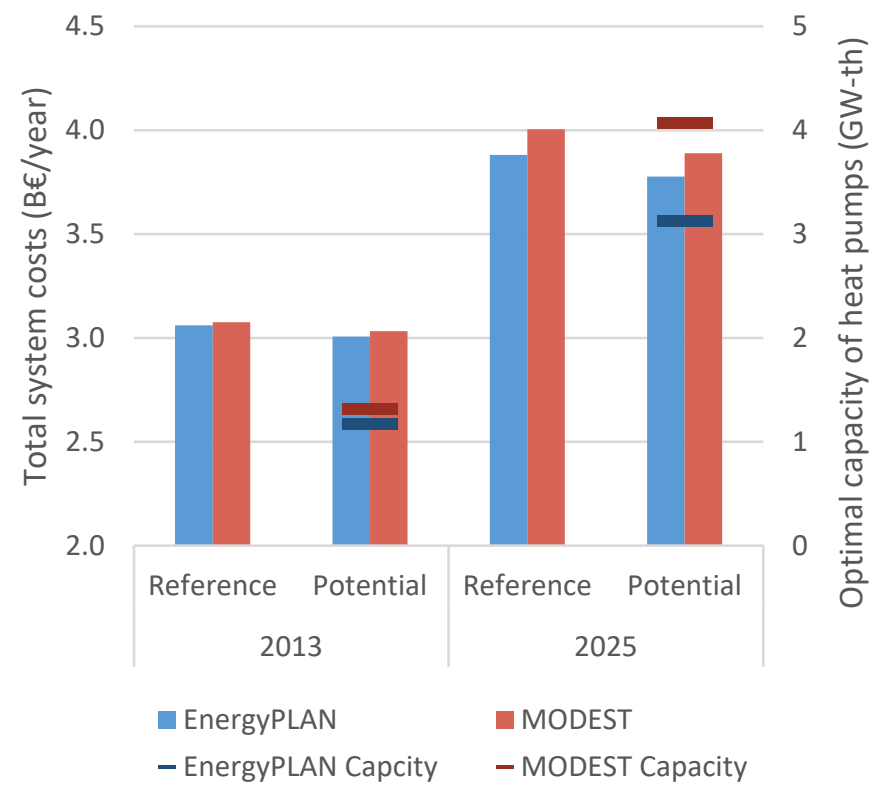

Figure 4 Main results of the two scenarios, 2013 and 2025, showing the optimal heat pump capacities in the calculation of the heat pump potential and the total system costs. Line markers indicate optimal capacity of heat pumps.

Figure 4 shows the results of the closed system analysis. Here, it can be seen that the costs are higher when electricity trade is not included but also that the differences between MODEST and EnergyPLAN results are minor. It can also be seen that the escalation in the feasible HP capacity, from 2013 to 2025, is about halved in the closed system analysis, which means that the HP capacity is sensitive to electricity market conditions.

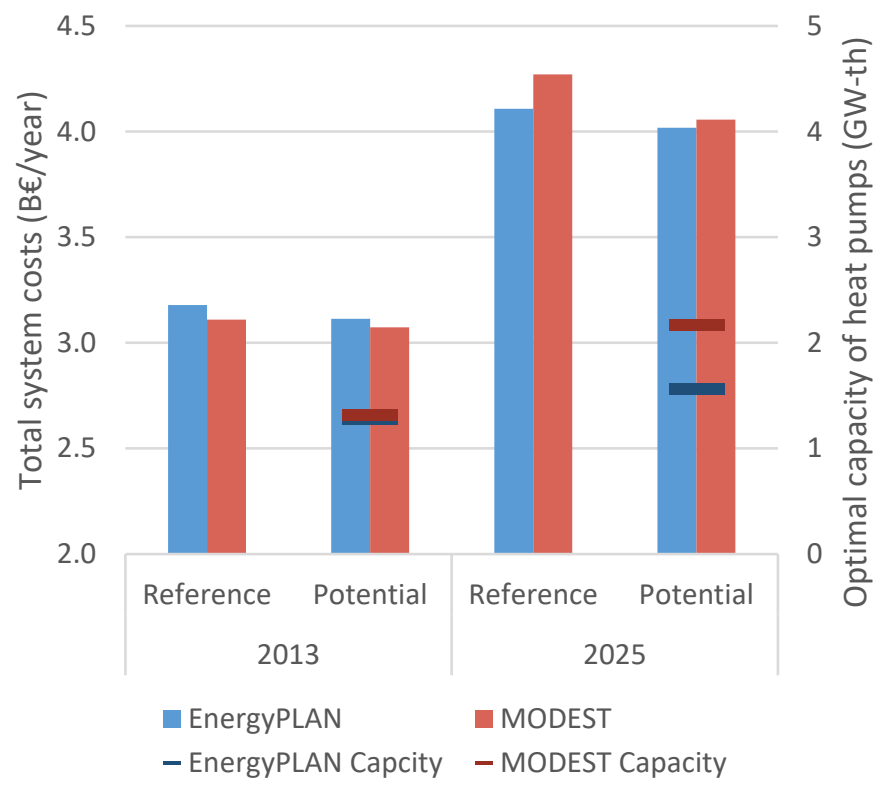

Figure 5 Results of a closed system analysis (excluding electricity exchange) for the two scenarios, 2013 and 2025, showing the optimal heat pump capacities in the calculation of the heat pump potential. Line markers indicate optimal capacity of heat pumps. 
The diagram in Figure 5 shows the relation between HP capacity and total system costs for the 2025 scenario both for base line and closed system calculations. Here, the optimal values seen in Figure 3 and Figure 4 are indicated with circles in the graphs. It can be seen that the tendencies in the results are similar for the two tools both for base line and closed system calculations. The costs identified by MODEST are generally higher than for EnergyPLAN, 0.02-0.12 B€/year, but the tendencies are similar and the tools identify optimal capacities in the same order of magnitude.

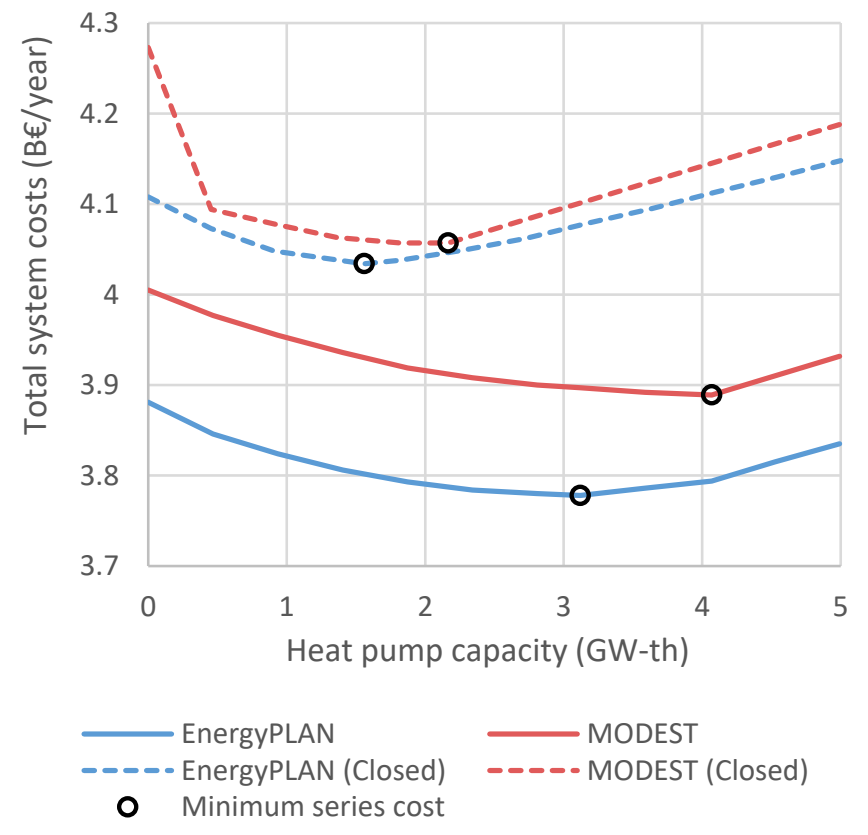

Figure 6 Trends in total system costs in the 2025 scenario with increasing heat pump capacity; for the base line calculations and for closed system calculations.

\subsection{Sensitivity to Changes in Assumptions and Modelling}

The results of the main sensitivity analyses are presented in Figure 6 . Here, the consequences of applying alternative high and low values of central analysis parameters, can be seen. More details in Table 6 in the Appendix.

Changes in the electricity and fuel price levels both show relatively high sensitivity, because the optimal capacity goes from more than $5 \mathrm{GW}$ to almost $0 \mathrm{GW}$. It is important to notice that it is the relative change between the electricity and fuel prices that is important, because in the two cases, the supply of DH shifts from being mainly based on electricity (by HPs) to being based on the combustion of fuels. This means that if, for example, both fuel and electricity prices follow a similar development trend, either increasing or decreasing, the optimal capacity of HPs will not change significantly.

The results are less sensitive to changes in the investment costs and the COP of the HPs. This can be seen as the optimal HP capacities differ less than changes in the energy prices. This means that no matter if the investment costs of HPs decrease and no matter if an average COP of only 2.5 can be obtained, a capacity of around 1.0 $\mathrm{GW}$ is still feasible. 


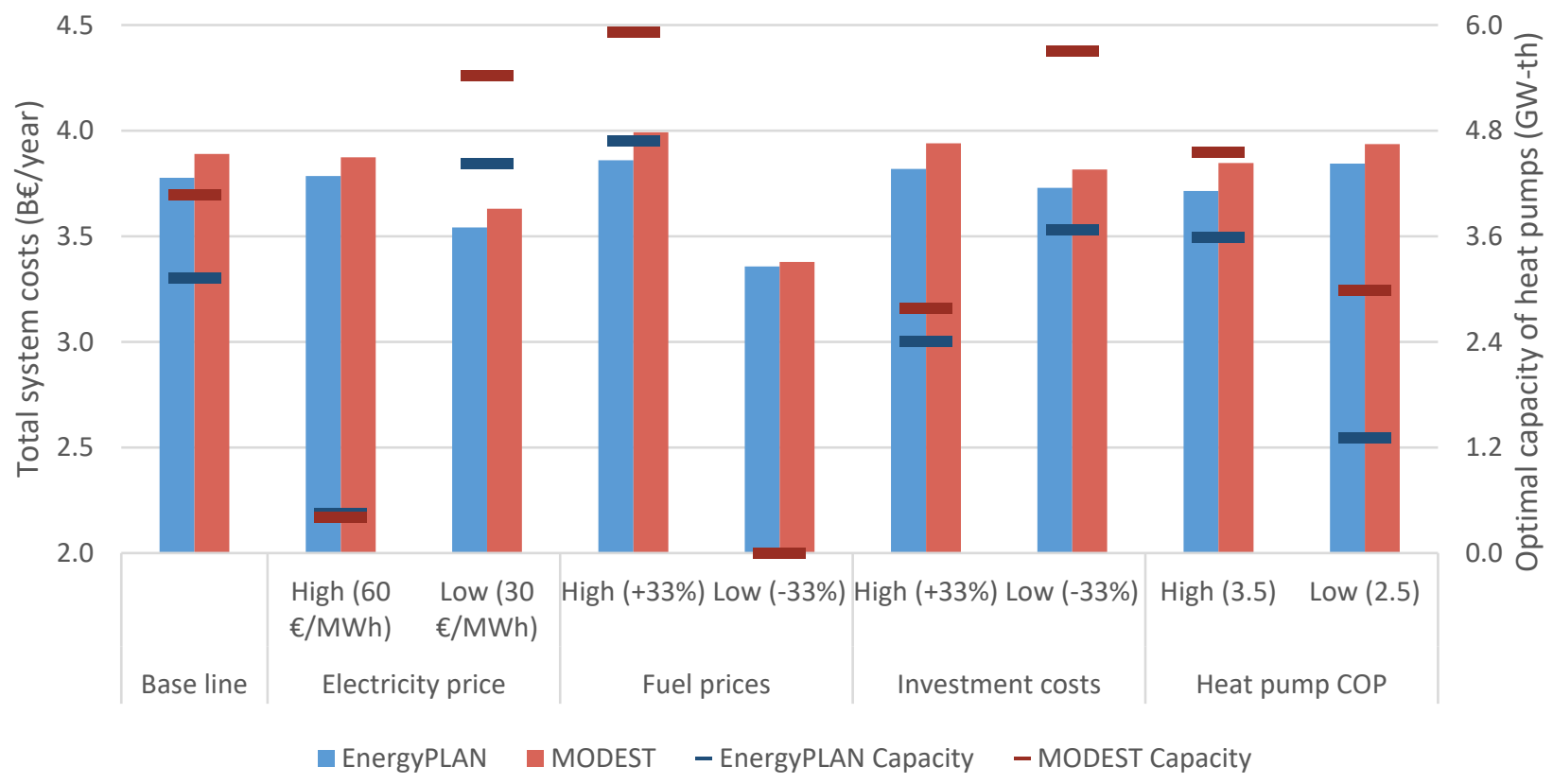

Figure 7 Diagram showing the sensitivity of the results to a number of central analysis parameters in the 2025 scenario. Line markers indicate optimal capacity of heat pumps.

The results of four central sensitivity analyses are presented, but the sensitivity to other variables have been tested in connection with this study as well. This includes $\mathrm{CO}_{2}$-emission costs, discount rate of investments and wind power penetration. However, none of the other tested variable showed remarkable sensitivity, and are therefore not included in this paper. Other central assumptions are discussed in the following section.

\subsection{Discussion}

In this study, it has been assumed that heat sources for HPs are available at unlimited capacities whenever needed for heat production, but the heat sources may in reality be a limiting factor to the possible capacities. Lund and Persson have in (Lund and Persson, 2016) mapped eight different potential heat sources for large HPs in $\mathrm{DH}$. They conclude that heat sources are available in nearly $99 \%$ of all $\mathrm{DH}$ networks in Denmark without quantifying the time dependency of the heat source capacity. This indicates that it might be possible to achieve heat sources for large capacities of HPs, but the changes in the heat sources during the year should be analysed to determine the annual changes in potential capacity and COP.

As discussed in Section 2.3, Lund (2014) argues that the modelling of energy systems with a large integration of fluctuating RE sources should be performed using at least an hourly temporal resolution. This is in order to provide a sufficient representation of the fluctuations and the impact of these on the energy system. This study shows, on the other hand, that an analysis using only 96 time divisions in MODEST, compared to 8784 in EnergyPLAN, produces very similar results of system operation, fuel consumption and costs. This indicates that hourly modelling may not be necessary at large-scale integration. 100\% RE systems with large-scale energy storage will likely have a higher need for detailed temporal modelling and up to 99 time divisions may not be sufficient in this case, but that is not analysed here. 
Denmark is not the only country with a large interest in wind power. Most of Denmark's neighbouring countries are also building wind farms with increasing sizes. Europe's largest onshore wind farm of $1 \mathrm{GW}$ has recently been announced for construction in Norway (Statkraft, 2016) and the world's biggest offshore wind farm of 1.2 GW has also recently been announced for construction in the UK (DONG Energy, 2016). This means that the economic potential for import and export of electricity will be limited because of the similarities in weather patterns in different countries. Rodríguez et al. (2014) have analysed how electricity interconnection affects the integration of $100 \%$ fluctuating renewables in Europe and found that the need for back-up power can only be reduced from 24 to $15 \%$ from no interconnection to a fully-interconnected Europe. Similarly, $\varnothing$ stergaard (2008) found that the effect of interconnection between countries with high wind power penetration is limited, taking into account the temporal difference in the occurrence of the fluctuations. This is important to keep in mind because, as shown in this analysis, HP capacities above $2 \mathrm{GW}$ of thermal power will be dependent on external electricity trade. The capacity of $2 \mathrm{GW}$ found in the closed system analysis shows only the potential for the Danish energy system, whereas the $4 \mathrm{GW}$ found in the base line analysis depends on the trade of electricity at the assumed price level. The $4 \mathrm{GW}$ can therefore be seen as a good level, according to an optimistic perspective on the development of the energy price levels, whereas the $2 \mathrm{GW}$ found in the closed system analysis can be seen as a conservative level of HP capacity in Denmark.

On the basis of the results, it can be recommended to revise the current public regulation related to the business economy of HPs in DH. This is necessary because the current public regulation does not encourage investments in HPs for $\mathrm{DH}$, and that is a barrier to the realisation of the socioeconomic potential shown in this study.

\section{Conclusions}

The study shows that there is a socioeconomic potential for introducing HPs in DH in Denmark already today of up to $50 \mathrm{M} € /$ year and increasing to $100 \mathrm{M} € /$ year towards 2025. The optimal capacity appear to be in the range between 2 and $4 \mathrm{GW}$ of thermal power. The application and results of the two tools EnergyPLAN and MODEST have been compared, but this comparison does not show any significant differences. The main difference found is that EnergyPLAN generally suggests lower HP capacities and identifies lower total system costs than MODEST.

Sensitivity analyses show that the results are sensitive to electricity and fuel price levels; thus, if the electricity prices increase relative to the fuel price levels, the potential for HPs will decrease and vice versa. The sensitivity to changes in HP investment costs and COP are significantly lower than for the energy prices, and changes in these parameters are not seen as a risk to the feasibility of HPs.

\section{Acknowledgement}

The authors would like to greatly thank Dag Henning and Shahnaz Amiri for valuable inputs and discussion on the use of the MODEST tool and Bahram Moshfegh for hosting Rasmus Lund as a visiting researcher in the Division of Energy Systems at Linköping University.

The work presented in this paper is a result of the research activities of the Strategic Research Centre for $4^{\text {th }}$ Generation District Heating (4DH), which has received funding from The Innovation Fund Denmark. 


\section{References}

Andersen, A.N., Lund, H., 2007. New CHP partnerships offering balancing of fluctuating renewable electricity productions. J. Clean. Prod. 15, 288-293. doi:10.1016/j.jclepro.2005.08.017

Bach, B., Werling, J., Ommen, T., Münster, M., Morales, J.M., Elmegaard, B., 2016. Integration of large-scale heat pumps in the district heating systems of Greater Copenhagen. Energy 107, 321-334.

Blarke, M.B., 2012. Towards an intermittency-friendly energy system: Comparing electric boilers and heat pumps in distributed cogeneration. Appl. Energy 91, 349-365. doi:10.1016/j.apenergy.2011.09.038

Blarke, M.B., Dotzauer, E., 2011. Intermittency-friendly and high-efficiency cogeneration: Operational optimisation of cogeneration with compression heat pump, flue gas heat recovery, and intermediate cold storage. Energy 36, 6867-6878. doi:10.1016/j.energy.2011.10.008

Churchman, C.W., 1968. The Systems Approach. Delacorte Press, New York, USA.

Clausen, K.S., From, N., Hofmeiseter, M., Paaske, B.L., Flørning, J., 2014. Inspirational Catalogue for Large Heat Pumps in the District Heating System (Inspirationskatalog for store varmepumper i fjernvarmesystemet). Danish District Heating Association.

Connolly, D., Lund, H., Mathiesen, B. V, Leahy, M., 2010. A review of computer tools for analysing the integration of renewable energy into various energy systems. Appl. Energy 87, 1059-1082. doi:10.1016/j.apenergy.2009.09.026

Connolly, D., Mathiesen, B.V., 2014. A technical and economic analysis of one potential pathway to a $100 \%$ renewable energy system. Int. J. Sustain. Energy Plan. Manag. 1, 7-28.

Danish Energy Agency, 2015a. Årlig Energistatistik 2014 (Annual energy statistics 2014). Danish Energy Agency.

Danish Energy Agency, 2015b. Technology Data for Energy Plants. Generation of Electricity and District Heating, Energy Storage and Energy Carrier Generation and Conversion. - certain updates made October 2013, January 2014 and March 2015. Copenhagen.

Danish Energy Agency, 2014a. Årlig Energistatistik 2013 (Annual energy statistics 2013). Danish Energy Agency.

Danish Energy Agency, 2014b. Danmarks energi- og klimafremskrivning 2014 (Denmark's energy and climate projection 2014). Danish Energy Agency.

Danish Energy Agency, 2013. Energipriser og -afgifter (Energy prices and levies) [WWW Document]. URL http://www.ens.dk/info/tal-kort/statistik-nogletal/energipriser-afgifter (accessed 2.22.16).

DONG Energy, 2016. World's largest ever offshore wind farm to be built by DONG Energy [WWW Document]. URL http://www.dongenergy.co.uk/news/press-releases/articles/worlds-largest-ever-offshore-wind-farmto-be-built-by-dong-energy (accessed 2.26.16).

Dyrelund, A., Fafner, K., Ulbjerg, F., Knudsen, S., Lund, H., Mathiesen, B., Hvelplund, F., Bojesen, C., Odgaard, A., Sørensen, R., 2010. Varmeplan Danmark 2010 Forudsætningskatalog for samfunds $\varnothing$ konomi-. Aalborg Universitet.

Energinet.dk, 2015. Energinet.dk's analyseforudsætninger 2015-2035 (Energinet.dk's analysis assumptions 2015.2035). Energinet.dk (Danish TSO). 
Gebremedhin, A., 2003. Regional and industrial co-operation in district heating systems. Dissertation no. 849. Linköping University.

Henning, D., 1999. Optimisation of Local and National Energy Systems. Development and use of the MODEST model. Dissertation no. 559. Linköping University.

Henning, D., Amiri, S., Holmgren, K., 2006. Modelling and optimisation of electricity, steam and district heating production for a local Swedish utility. Eur. J. Oper. Res. 175, 1224-1247.

Ingelstam, L., Swedish Energy, 2002. System - att tänka över samhälle och teknik (System - thinking about society and technology, in Swedish). Kristianstad, Sweden.

Karschin, I., Geldermann, J., 2015. Efficient cogeneration and district heating systems in bioenergy villages: an optimization approach. J. Clean. Prod. 104, 305-314.

Lund, H., 2014. Renewable Energy Systems : A Smart Energy Systems Approach to the Choice and Modeling of 100\% Renewable Solutions. Academic Press, Burlington, USA.

Lund, R., Persson, U., 2016. Mapping of potential heat sources for heat pumps for district heating in Denmark. Energy. doi:10.1016/j.energy.2015.12.127

Mathiesen, B.V., Lund, H., Connolly, D., 2012. Limiting biomass consumption for heating in $100 \%$ renewable energy systems. Energy. doi:10.1016/j.energy.2012.07.063

Mathiesen, B.V., Lund, H., Connolly, D., Wenzel, H., Østergaard, P.A.P.A., Möller, B., Nielsen, S., Ridjan, I., Karnøe, P., Sperling, K., Hvelplund, F.K.F., 2015a. Smart Energy Systems for coherent $100 \%$ renewable energy and transport solutions. Appl. Energy 145, 139-154. doi:10.1016/j.apenergy.2015.01.075

Mathiesen, B.V., Lund, H., Hansen, K., Ridjan, I., Djørup, S., Nielsen, S., Sorknæs, P., Thellufsen, J.Z., Grundahl, L., Lund, R., Drysdale, D., Connolly, D., Østergaard, P.A., 2015b. IDA's Energy Vision 2050 - Technical data and methods.

Nielsen, S.N., Jørgensen, S.E., 2015. Sustainability analysis of a society based on exergy studies - a case study of the island of Sams $\varnothing$ (Denmark). J. Clean. Prod. 96, 12-29.

Ommen, T., Markussen, W.B., Elmegaard, B., 2014. Heat pumps in combined heat and power systems. Energy 76, 989-1000.

Østergaard, P.A., 2008. Geographic aggregation and wind power output variance in Denmark. Energy 33, 14531460.

Pensini, A., Rasmussen, C.N., Kempton, W., 2014. Economic analysis of using excess renewable electricity to displace heating fuels. Appl. Energy 131, 530-543. doi:http://dx.doi.org/10.1016/j.apenergy.2014.04.111

Rodríguez, R.A., Becker, S., Andresen, G.B., Heide, D., Greiner, M., 2014. Transmission needs across a fully renewable European power system. Renew. Energy 63, 467-476.

doi:http://dx.doi.org/10.1016/j.renene.2013.10.005

Segurado, R., Pereira, S., Pipio, A., Alves, L., 2009. Comparison between EMINENT and other energy technology assessment tools. J. Clean. Prod. 17, 907-910.

Statkraft, 2016. Europe's largest onshore wind power project to be built in Central-Norway [WWW Document]. 
URL http://www.statkraft.com/IR/stock-exchange-notice/2016/europes-largest-onshore-wind-powerproject--to-be-built-in-central-norway--/ (accessed 2.26.16).

The Danish Government, 2012. The Energy Agreement 2012 (Energiaftalen 22. marts 2012).

Wallén, G., 1996. Vetenskapsteori och forskningsmetodik. Studentlitteratur, Lund, Sweden. 


\section{Appendix: Simulation Output Data}

Table 5 Operational data from the key calculations from EnergyPLAN (EP) and MODEST (MO) for the scenarios 2013 and 2025 in the base line and closed system calculations. Identified optimal capacities of electric boilers and heat pumps under "Capacities."

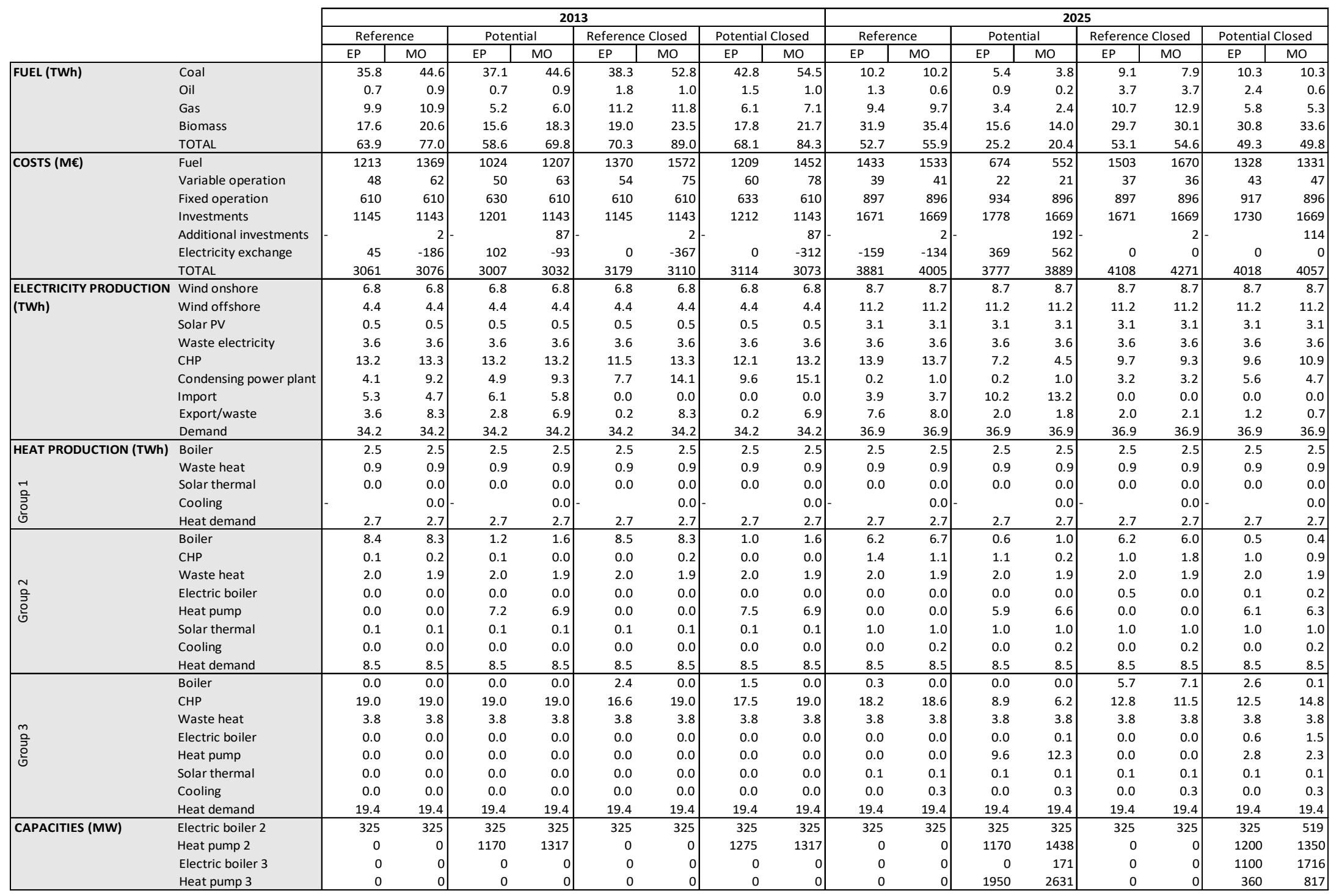


Table 6 Operational data from the key calculations from EnergyPLAN (EP) and MODEST (MO) for the scenario 2025 in the sensitivity analysis calculations. Identified optimal capacities of electric boilers and heat pumps under "Capacities."

\begin{tabular}{|c|c|c|c|c|c|c|c|c|c|c|c|c|c|c|c|c|c|}
\hline & & \multirow{2}{*}{\multicolumn{16}{|c|}{ Sensitivity analyses: 2025}} \\
\hline & & & & & & & & & & & & & & & & & \\
\hline & & \multicolumn{2}{|c|}{ Electricity price: High } & \multicolumn{2}{|c|}{\begin{tabular}{|l|} 
Electricity pric: Low \\
\end{tabular}} & \multicolumn{2}{|c|}{ Fuel price: High } & \multicolumn{2}{|c|}{ Fuel price: Low } & \multicolumn{4}{|c|}{ nvestment costs: Highnvestment costs: Low } & \multicolumn{2}{|c|}{ COP: High } & \multicolumn{2}{|c|}{ COP: Low } \\
\hline & & EP & MO & EP & $\mathrm{MO}$ & EP & MO & EP & MO & EP & $\mathrm{MO}$ & EP & $\mathrm{MO}$ & EP & $\mathrm{MO}$ & EP & $\mathrm{MO}$ \\
\hline \multirow[t]{5}{*}{ FUEL (TWh) } & Coal & 11.6 & 14.2 & 2.5 & 1.1 & 2.6 & 1.1 & 12.5 & 16.2 & 6.4 & 5.3 & 4.8 & 2.6 & 4.3 & 3.2 & 8.6 & 5.8 \\
\hline & Oil & 1.2 & 0.8 & 0.8 & 0.1 & 0.8 & 0.1 & 1.3 & 0.9 & 1.0 & 0.3 & 0.9 & 0.1 & 0.8 & 0.2 & 1.1 & 0.3 \\
\hline & Gas & 10.1 & 13.5 & 0.7 & 0.7 & 0.7 & 0.6 & 13.8 & 17.1 & 4.2 & 3.3 & 3.5 & 1.1 & 3.1 & 1.7 & 5.5 & 3.2 \\
\hline & Biomass & 35.3 & 47.1 & 6.4 & 5.8 & 6.7 & 5.7 & 38.9 & 53.6 & 18.7 & 18.9 & 13.7 & 10.2 & 12.3 & 12.1 & 25.7 & 20.0 \\
\hline & TOTAL & 58.2 & 75.6 & 10.3 & 7.6 & 10.8 & 7.5 & 66.4 & 87.8 & 30.2 & 27.9 & 22.8 & 14.1 & 20.6 & 17.2 & 40.8 & 29.3 \\
\hline \multirow[t]{7}{*}{ COSTS (M€) } & Fuel & 1573 & 2068 & 272 & 208 & 367 & 274 & 1216 & 1612 & 809 & 752 & 615 & 378 & 554 & 463 & 1090 & 787 \\
\hline & Variable operation & 50 & 66 & 9 & 12 & 10 & 12 & 57 & 78 & 26 & 26 & 20 & 17 & 18 & 19 & 33 & 28 \\
\hline & Fixed operation & 902 & 896 & 950 & 896 & 953 & 896 & 897 & 896 & 935 & 896 & 926 & 896 & 934 & 896 & 916 & 896 \\
\hline & Investments & 1686 & 1669 & 1826 & 1669 & 1832 & 1669 & 1671 & 1669 & 1781 & 1669 & 1755 & 1669 & 1777 & 1669 & 1725 & 1669 \\
\hline & Additional investments & - & 21 . & & 259 & & 280 & & 2 & & 181 & & 179 & & 213 & & 147 \\
\hline & Electricity exchange & -426 & -844 & 485 & 586 & 698 & 865 & -484 & -876 & 268 & 418 & 413 & 679 & 431 & 589 & 80 & 412 \\
\hline & TOTAL & 3785 & 3874 & 3542 & 3631 & 3860 & 3993 & 3357 & 3379 & 3819 & 3940 & 3729 & 3816 & 3714 & 3847 & 3844 & 3936 \\
\hline \multirow{9}{*}{$\begin{array}{l}\text { ELECTRICITY PRODUCTION } \\
\text { (TWh) }\end{array}$} & Wind onshore & 8.7 & 8.7 & 8.7 & 8.7 & 8.7 & 8.7 & 8.7 & 8.7 & 8.7 & 8.7 & 8.7 & 8.7 & 8.7 & 8.7 & 8.7 & 8.7 \\
\hline & Wind offshore & 11.2 & 11.2 & 11.2 & 11.2 & 11.2 & 11.2 & 11.2 & 11.2 & 11.2 & 11.2 & 11.2 & 11.2 & 11.2 & 11.2 & 11.2 & 11.2 \\
\hline & Solar PV & 3.1 & 3.1 & 3.1 & 3.1 & 3.1 & 3.1 & 3.1 & 3.1 & 3.1 & 3.1 & 3.1 & 3.1 & 3.1 & 3.1 & 3.1 & 3.1 \\
\hline & Waste electricity & 3.6 & 3.6 & 3.6 & 3.6 & 3.6 & 3.6 & 3.6 & 3.6 & 3.6 & 3.6 & 3.6 & 3.6 & 3.6 & 3.6 & 3.6 & 3.6 \\
\hline & $\mathrm{CHP}$ & 16.0 & 16.7 & 2.6 & 1.6 & 2.8 & 1.5 & 17.5 & 18.0 & 8.7 & 6.7 & 6.5 & 2.8 & 5.7 & 3.7 & 11.6 & 7.2 \\
\hline & Condensing power plant & 2.1 & 7.5 & 0.0 & 0.0 & 0.1 & 0.0 & 3.3 & 10.7 & 0.2 & 1.0 & 0.2 & 1.0 & 0.3 & 1.0 & 0.3 & 1.0 \\
\hline & Import & 2.3 & 1.7 & 16.4 & 18.5 & 16.1 & 18.1 & 1.2 & 1.2 & 8.7 & 10.1 & 11.0 & 15.5 & 11.3 & 13.6 & 6.2 & 10.2 \\
\hline & Export/waste & 9.1 & 14.8 & 1.3 & 0.9 & 1.3 & 0.9 & 11.6 & 19.3 & 2.8 & 1.6 & 1.8 & 1.5 & 1.8 & 1.9 & 4.5 & 1.5 \\
\hline & Demand & 36.9 & 36.9 & 36.9 & 36.9 & 36.9 & 36.9 & 36.9 & 36.9 & 36.9 & 36.9 & 36.9 & 36.9 & 36.9 & 36.9 & 36.9 & 36.9 \\
\hline \multirow[t]{5}{*}{ HEAT PRODUCTION (TWh) } & Boiler & 2.5 & 2.5 & 2.5 & 2.5 & 2.5 & 2.5 & 2.5 & 2.5 & 2.5 & 2.5 & 2.5 & 2.5 & 2.5 & 2.5 & 2.5 & 2.5 \\
\hline & Waste heat & 0.9 & 0.9 & 0.9 & 0.9 & 0.9 & 0.9 & 0.9 & 0.9 & 0.9 & 0.9 & 0.9 & 0.9 & 0.9 & 0.9 & 0.9 & 0.9 \\
\hline & Solar thermal & 0.0 & 0.0 & 0.0 & 0.0 & 0.0 & 0.0 & 0.0 & 0.0 & 0.0 & 0.0 & 0.0 & 0.0 & 0.0 & 0.0 & 0.0 & 0.0 \\
\hline & Cooling & 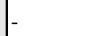 & 0.0 . & & 0.0 & & 0.0 & & 0.0 & & 0.0 . & & 0.0 & & 0.0 & & 0.0 \\
\hline & Heat demand & 2.7 & 2.7 & 2.7 & 2.7 & 2.7 & 2.7 & 2.7 & 2.7 & 2.7 & 2.7 & 2.7 & 2.7 & 2.7 & 2.7 & 2.7 & 2.7 \\
\hline \multirow{8}{*}{ 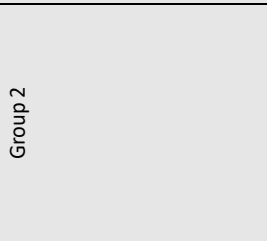 } & Boiler & 1.5 & 1.1 & 0.4 & 0.1 & 0.2 & 0.0 & 2.5 & 1.4 & 0.8 & 1.5 & 0.4 & 0.0 & 0.5 & 0.4 & 2.0 & 1.2 \\
\hline & $\mathrm{CHP}$ & 3.5 & 5.1 & 0.1 & 0.0 & 0.2 & 0.0 & 5.1 & 6.8 & 1.3 & 0.3 & 1.4 & 0.0 & 1.2 & 0.1 & 1.2 & 0.2 \\
\hline & Waste heat & 2.0 & 1.9 & 2.0 & 1.9 & 2.0 & 1.9 & 2.0 & 1.9 & 2.0 & 1.9 & 2.0 & 1.9 & 2.0 & 1.9 & 2.0 & 1.9 \\
\hline & Electric boiler & 0.0 & 0.0 & 0.0 & 0.4 & 0.0 & 0.0 & 0.0 & 0.0 & 0.0 & 0.0 & 0.0 & 0.0 & 0.0 & 0.0 & 0.0 & 0.0 \\
\hline & Heat pump & 2.6 & 2.0 & 7.1 & 7.3 & 7.2 & 7.8 & 0.0 & 0.0 & 5.5 & 6.1 & 5.9 & 7.8 & 6.0 & 7.3 & 4.5 & 6.4 \\
\hline & Solar thermal & 1.0 & 1.0 & 1.0 & 1.0 & 1.0 & 1.0 & 1.0 & 1.0 & 1.0 & 1.0 & 1.0 & 1.0 & 1.0 & 1.0 & 1.0 & 1.0 \\
\hline & Cooling & 0.0 & 0.4 & 0.0 & 0.2 & 0.0 & 0.2 & 0.0 & 0.4 & 0.0 & 0.2 & 0.0 & 0.2 & 0.0 & 0.2 & 0.0 & 0.2 \\
\hline & Heat demand & 8.5 & 8.5 & 8.5 & 8.5 & 8.5 & 8.5 & 8.5 & 8.5 & 8.5 & 8.5 & 8.5 & 8.5 & 8.5 & 8.5 & 8.5 & 8.5 \\
\hline & Boiler & 0.0 & 0.0 & 0.0 & 0.0 & 0.1 & 0.0 & 0.0 & 0.0 & 0.0 & 0.0 & 0.0 & 0.0 & 0.0 & 0.0 & 0.1 & 0.0 \\
\hline & CHP & 18.5 & 18.6 & 3.6 & 2.2 & 3.7 & 2.2 & 18.5 & 18.6 & 10.8 & 9.3 & 7.6 & 4.0 & 6.7 & 5.2 & 15.1 & 10.1 \\
\hline & Waste heat & 3.8 & 3.8 & 3.8 & 3.8 & 3.8 & 3.8 & 3.8 & 3.8 & 3.8 & 3.8 & 3.8 & 3.8 & 3.8 & 3.8 & 3.8 & 3.8 \\
\hline$\stackrel{m}{m}$ & Electric boiler & 0.0 & 0.0 & 0.0 & 0.7 & 0.0 & 0.3 & 0.0 & 0.0 & 0.0 & 0.9 & 0.0 & 0.0 & 0.0 & 0.0 & 0.0 & 0.8 \\
\hline \begin{tabular}{|l|l}
0 \\
$\frac{0}{5}$
\end{tabular} & Heat pump & 0.0 & 0.0 & 14.9 & 15.7 & 14.7 & 16.1 & 0.0 & 0.0 & 7.7 & 8.4 & 10.9 & 14.6 & 11.9 & 13.5 & 3.3 & 7.7 \\
\hline & Solar thermal & 0.1 & 0.1 & 0.1 & 0.1 & 0.1 & 0.1 & 0.1 & 0.1 & 0.1 & 0.1 & 0.1 & 0.1 & 0.1 & 0.1 & 0.1 & 0.1 \\
\hline & Cooling & 0.0 & 0.3 & 0.0 & 0.3 & 0.0 & 0.3 & 0.0 & 0.3 & 0.0 & 0.3 & 0.0 & 0.3 & 0.0 & 0.3 & 0.0 & 0.3 \\
\hline & Heat demand & 19.4 & 19.4 & 19.4 & 19.4 & 19.4 & 19.4 & 19.4 & 19.4 & 19.4 & 19.4 & 19.4 & 19.4 & 19.4 & 19.4 & 19.4 & 19.4 \\
\hline \begin{tabular}{|l|} 
CAPACITIES (MW) \\
\end{tabular} & Electric boiler 2 & 325 & 325 & 325 & 456 & 325 & 325 & 325 & 325 & 325 & 325 & 325 & 325 & 325 & 325 & 325 & 325 \\
\hline & Heat pump 2 & 450 & 403 & 1425 & 1748 & 1530 & 2014 & 0 & 0 & 1050 & 1242 & 1275 & 2025 & 1138 & 1748 & 750 & 1356 \\
\hline & Electric boiler 3 & 0 & 0 & 0 & 897 & 0 & 669 & 0 & 0 & 0 & 1261 & 0 & 0 & 0 & 0 & 0 & 1175 \\
\hline & Heat pump 3 & 0 & 0 & 3000 & 3671 & 3150 & 3899 & 0 & 0 & 1350 & 1541 & 2400 & 3671 & 2450 & 2802 & 562 & 1627 \\
\hline
\end{tabular}

